\title{
KAJIAN TUNDAAN LALU LINTAS PADA SIMPANG BERSINYAL (Studi Kasus: Simpang Jl. Brigjen Sudiarto - Jl. Majapahit - Jl. Fatmawati Kota Semarang)
}

\author{
Jayanti Rizqi Novianka P. ${ }^{\text {() }}$, Khrisna Dwi Hidayati ${ }^{1)}$, Supriyadi ${ }^{1)}$, Junaidi ${ }^{1{ }^{* *}}$ \\ ${ }^{1)}$ Jurusan Teknik Sipil Politeknik Negeri Semarang \\ Jl. Prof. Soedarto SH, Tembalang Semarang 50275 Telepon (024) 76480569 \\ ${ }^{*}$ Email: junaiditspolines@gmail.com
}

\begin{abstract}
Traffic volume in Semarang City has increased every year due to the increasing number of vehicles. Congestion that occurs at the T-junction intersection Jl. Brigjen Sudiarto - Jl. Majapahit is one of the impacts of high traffic growth and the traffic system is not functioning properly. By considering the geometric conditions of the road, traffic volume, side obstacles and the intersection environment which is a commercial area, it is necessary to analyze the cause of the congestion at the intersection. The research conducted was to conduct a field survey to obtain primary and secondary data which are then processed using intersection management. Planning uses the 1997 Indonesian Road Capacity Manual (MKJI) and uses the Excel 2013 program to process traffic data. Traffic data is obtained from recording the number of vehicles in the field for 3 days (April 29, 01 and May $4,2019)$ during peak hours and presented in the form of a vehicle data table, then the behavior of the intersection can be analyzed. From the analysis results obtained value of the degree of saturation (DS) at the intersection of Jl. Brigjen Sudiarto - Jl. Majapahit 0.991. This value has exceeded the required value by the 1997 MKJI, DS $\leq 0.85$. The analysis shows that the average traffic delay is $141,320 \mathrm{sec} / \mathrm{pcu}$, so this intersection has a Service Level (LOS) F (> 60).
\end{abstract}

Kata kunci : tundaan lalu lintas, derajat kejenuhan, simpang bersinyal

\section{PENDAHULUAN}

Kota Semarang merupakan ibukota Provinsi Jawa Tengah sekaligus kota metropolitan terbesar kelima di Indonesia setelah Jakarta, Surabaya, Medan dan Bandung. Kota Semarang mempunyai jumlah penduduk hampir mencapai 2 juta jiwa dan di siang hari bisa mencapai 2,5 juta jiwa. Dalam beberapa tahun terakhir, perkembangan Semarang yang signifikan ditandai pula dengan munculnya beberapa gedung pencakar langit yang tersebar di penjuru kota (BPS Jateng, 2018).

Seiring bertambahnya jumlah penduduk dari tahun ke tahun maka jumlah kendaraan juga ikut meningkat, hal ini dapat menyebabkan kepadatan lalu lintas yang berujung pada kemacetan. Salah satu permasalahan transportasi di Kota Semarang adalah kemacetan. Kemacetan di Kota Semarang sering terjadi pada beberapa titik, salah satunya persimpangan Jalan 
Brigjen Sudiarto - Jalan Majapahit Jalan Fatmawati.

Kemacetan pada jalan perkotaan maupun jalan luar kota diakibatkan karena fasilitas lalu lintas belum beroperasi dengan optimal, meningkatnya kegiatan ekonomi serta terbatasnya sumber daya alam untuk pembangunan jalan raya. Kemacetan akan terjadi ketika kapasitas jalan sudah tidak dapat menampung kendaraan yang melewati suatu ruas jalan, sehingga ruang pada jalan menjadi terbatas. Kecepatan akan semakin berkurang hingga volume/arus lalu lintas tidak dapat bertambah sehingga kondisi menjadi macet total, arus tidak bergerak dan kepadatan tinggi.

Kemacetan sering terjadi pada

Jalan Brigjen Sudiarto - Jalan Majapahit - Jalan Fatmawati dimana pergerakan lalu lintas cukup padat, jalan tersebut merupakan daerah komersial karena di daerah tersebut terdapat pusat perbelanjaan, restoran, pertokoan, kantor, sekolah dan lainlain. Jalan tersebut merupakan perbatasan Kota Semarang - Demak Purwodadi.

Kemacetan tidak hanya terjadi ketika hari libur, hari-hari biasa juga sering terjadi kepadatan. Hal ini dapat terjadi ketika jam-jam puncak yaitu pagi hari dimulai pukul 06.00, siang hari pukul 12.00 dan sore hari pada pukul 16.00. Penyebab kemacetan lainnya adalah adanya hambatan samping seperti pejalan kaki, angkutan umum, kendaraan non motor, kendaraan lain yang berhenti di depan pertokoan yang tidak memiliki lahan parkir, angkutan umum yang menurunkan penumpang sembarangan walaupun sudah disediakan tempat pemberhentian sendiri, kendaraan keluar masuk di lahan samping jalan juga berpengaruh terhadap arus lalu lintas. Jika tidak diimbangi dengan ruas jalan yang memadahi, maka kemacetan akan terus terjadi.

Tujuan dibuat persimpangan bersinyal adalah untuk mengurangi potensi konflik diantara kendaraan (termasuk pejalan kaki) dan sekaligus menyediakan kenyamanan maksimum dan kemudahan pergerakan bagi kendaraan (Khisty, 2003).

Oleh karena itu, penelitian ini dimaksudkan untuk mengetahui kinerja simpang bersinyal pada simpang Jalan Brigjen Sudiarto - Jalan Majapahit Jalan Fatmawati.

\section{Persimpangan}

Simpang adalah suatu area kritis pada suatu jalan yang merupakan tempat titik konflik dan tempat kemacetan karena bertemunya dua ruas jalan atau lebih (Pignarto, 1973). Simpang juga dapat diartikan sebagai titik pertemuan atau titik konflik berbagai arah dimana dua ruas jalan atau lebih saling bersimpangan, termasuk jalan dan fasilitas di tepi jalan untuk pergerakan lalu lintas di dalamnya. Menurut Morlok (1998) jenis simpang berdasarkan cara pengaturannya terdiri dari 2 jenis, yaitu :

1) Simpang bersinyal (signalized intersection)

2) Simpang tak bersinyal (unsignalized intersection) 


\section{Arus Lalu Lintas}

Arus lalu lintas adalah jumlah kendaraan bermotor yang melewati suatu titik pada jalan per satuan waktu, dinyatakan dalam kendaraan/jam (Qkend), smp/jam (Qsmp atau LHRT \{Lalu Lintas Harian Rata-Rata Tahunan\}) (Manual Kapasitas Jalan Indonesia 1997). Secara keseluruhan, arus lalu lintas dapat juga digambarkan dengan 4 parameter, yaitu :

1) Karakteristik volume lalu lintas

2) Kecepatan

3) Kerapatan

4) Derajat kejenuhan

\section{Kapasitas}

Menurut Manual Kapasitas Jalan Indonesia (1997) kapasitas didefinisikan sebagai arus maksimum yang dapat dipertahankan per satuan jam pada kondisi tertentu. Pengertian kapasitas simpang adalah maksimum kendaraan yang dapat melewati kaki simpang.

\section{Kondisi Arus Lalu Lintas}

Arus lalu-lintas untuk setiap pergerakan dikonversi dari kendaraan per jam menjadi satuan mobil penumpang (smp) dengan menggunakan ekivalen mobil penumpang (emp) untuk masingmasing pendekat terlindung dan terlawan.

\section{Arus Jenuh Dasar (So)}

Arus jenuh dasar adalah besarnya keberangkatan antrian di dalam pendekat selama kondisi ideal (smp/jam hijau). Untuk mencari nilai arus jenuh dasar dapat menggunakan perhitungan sebagai berikut :

So $=600 \times W e$

\section{Dimana,}

So (Saturation flow o) : arus jenuh dasar (smp/jam)

We (Width Effective) : lebar efektif pendekat (m)

\section{METODE PENELITIAN}

\section{Lokasi Penelitian}

Lokasi simpang yang dipilih untuk menjadi objek penelitian berada di Jalan Brigjen Sudiarto - Jalan Majapahit - Jalan Fatmawati. Lokasi survei dapat dilihat pada Gambar 1.

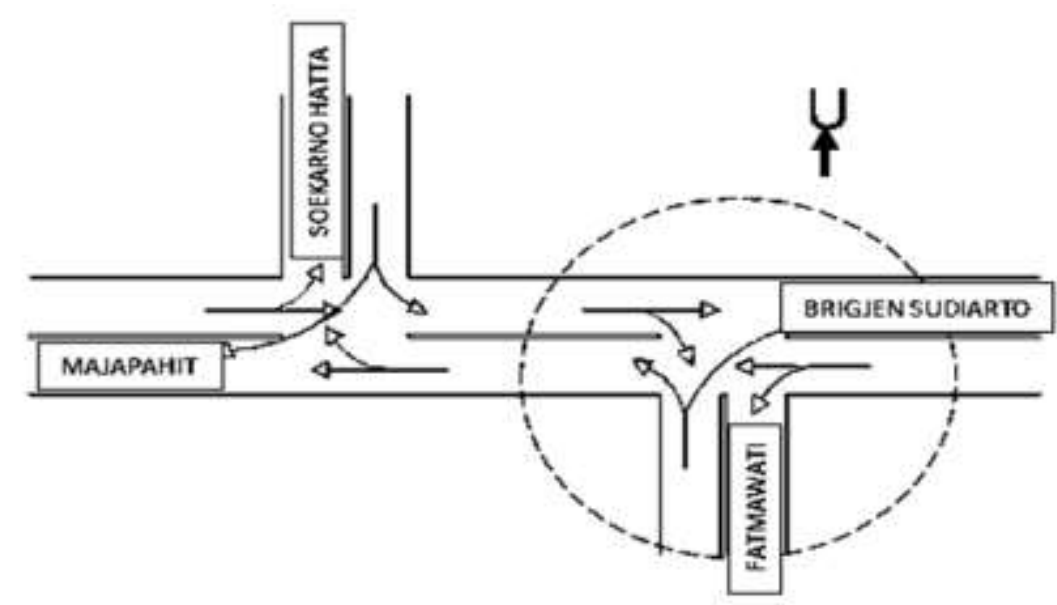

Gambar 1. Peta lokasi survei 


\section{Pengambilan Data Primer}

Data primer adalah sumber data yang diperoleh secara langsung dari serangkaian percobaan yang dilakukan sendiri dengan mengacu pada petunjuk manual yang ada. Pengambilan data dilaksanakan pada pagi hari yakni pukul 06.00 - 08.00 karena adanya kegiatan berangkat sekolah, bekerja dan kegiatan lainnya. Kemudian dilanjut pada siang hari yakni pukul 11.00 - 13.00 karena jam pulang sekolah, jam istirahat kantor dan kegiatan lainnya. Pada sore hari dimulai pada pukul 16.00 - 18.00 karena jam pulang kantor dan kegiatan lainnya. Pengambilan data yang dilakukan untuk mendapatkan data primer adalah :

1) Data geometrik

2) Data volume lalu lintas

3) Data antrian

4) Data tundaan

5) Survei hambatan samping

\section{Pengambilan Data Sekunder}

Data sekunder adalah sumber data yang diperoleh dan disatukan dari studi-studi sebelumnya dan yang diterbitkan oleh berbagai instansi. Data sekunder biasanya berupa sumber tidak langsung yang berupa data dokumentasi dan arsip-arsip resmi dari instansi. Data yang diperlukan untuk mendukung penelitian ini adalah data jumlah penduduk Kota Semarang bersumber dari Badan Pusat Statistik Provinsi Jawa Tengah, data LHR dan Geometrik Jalan Majapahit berdasarkan sumber dari Dinas Bina Marga dan Cipta Karya Povinsi Jawa Tengah. Bagan Alir Penelitian ini dapat dilihat pada Gambar 2 di bawah.

\section{HASIL DAN PEMBAHASAN}

Data geometrik jalan pada Simpang Brigjen Sudiarto dapat dilihat pada Tabel 5, sedangkan peta situasi daerah simpang Jalan Brigjen Sudiarto - Jalan Majapahit - Jalan Fatmawati dapat dilihat pada Gambar 3 di bawah. Waktu sinyal yang telah disesuaikan dan waktu siklus tiap fase disajikan dalam Tabel 6. Dari data survei lapangan diperoleh data kendaraan 1 jam tertinggi seperti dapat dilihat pada Tabel 7 di bawah.

Tabel 5. Kondisi Geometrik Jalan Simpang Brigjen Sudiarto

\begin{tabular}{lcccc}
\hline \multicolumn{1}{c}{ Nama Jalan } & $\begin{array}{c}\text { Kode } \\
\text { Pendekat }\end{array}$ & Median & $\begin{array}{c}\text { Belok } \\
\text { Kiri }\end{array}$ & $\begin{array}{c}\text { Lebar Pendekat } \\
(\mathrm{m})\end{array}$ \\
\hline Brigjen Sudiarto - Majapahit & T-ST & - & - & 10,100 \\
Brigjen Sudiarto - Fatmawati & T-LT & - & Ya & 9,400 \\
Majapahit - Brigjen Sudiarto & B-ST & - & - & 14,200 \\
Majapahit - Fatmawati & B-RT & - & - & 9,700 \\
Fatmawati - Brigjen Sudiarto & S-RT & - & - & 7,200 \\
Fatmawati - Majapahit & S-LT & - & - & 7,200 \\
\hline
\end{tabular}




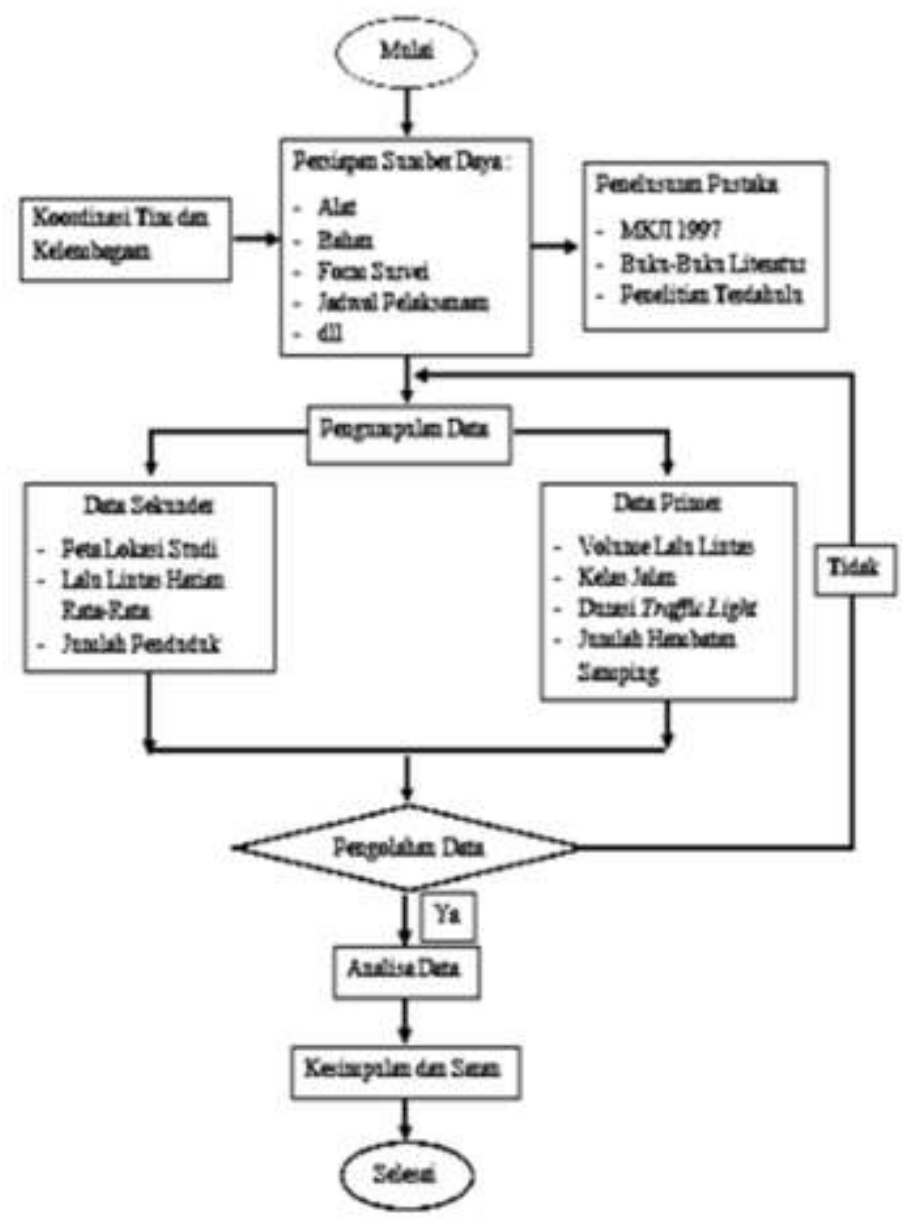

Gambar 2. Bagan Alir Penelitian

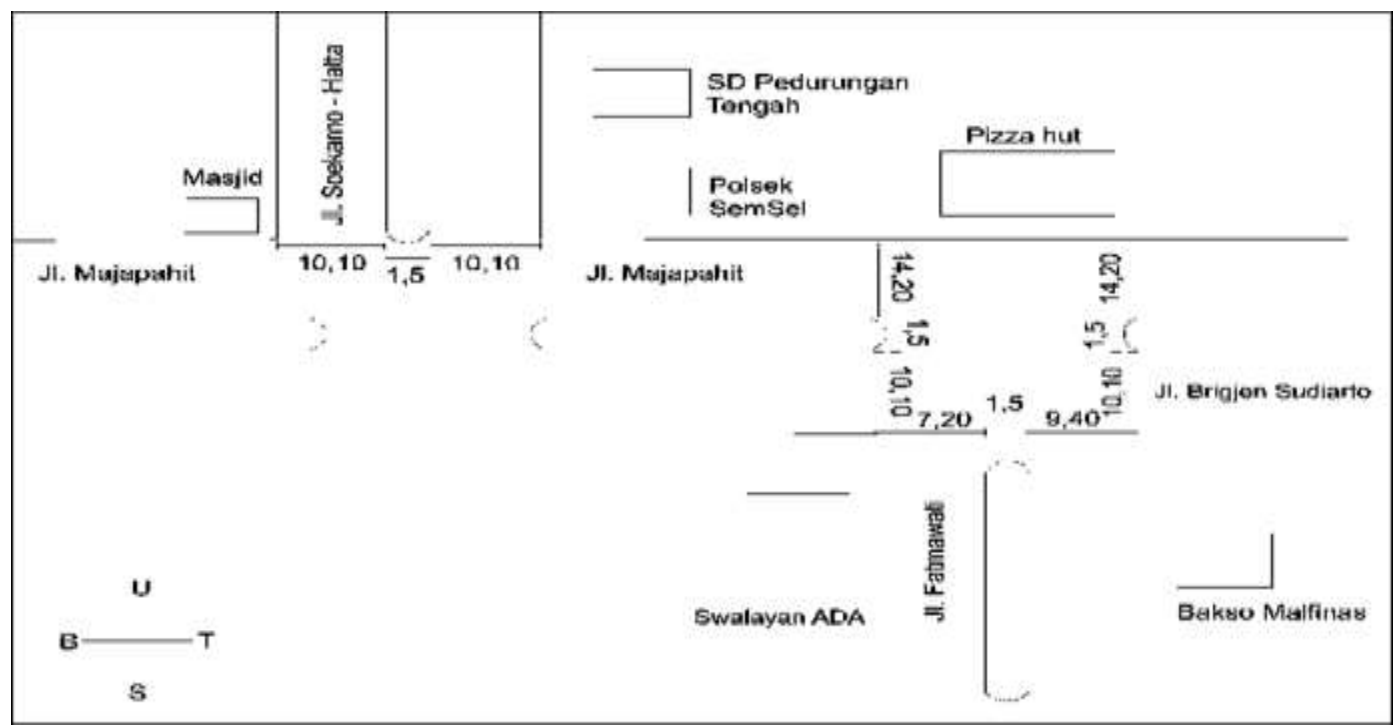

Gambar 3. Geometrik Jl. Brigjen Sudiarto - Jl. Jalan Majapahit 
Tabel 6. Waktu Siklus Sinyal

\begin{tabular}{lcccc}
\hline \multirow{2}{*}{\multicolumn{1}{c}{ Nama Jalan }} & \multicolumn{3}{c}{ Waktu Sinyal (det) } & \multirow{2}{*}{ Waktu Siklus (det) } \\
\cline { 2 - 4 } & M & H & K & \\
\hline Brigjen Sudiarto - Majapahit & 92 & 70 & 3 & 165 \\
Brigjen Sudiarto - Fatmawati & 92 & 70 & 3 & 165 \\
Majapahit - Brigjen Sudiarto & - & - & - & - \\
Majapahit - Fatmawati & 97 & 65 & 3 & 165 \\
Fatmawati - Brigjen Sudiarto & 132 & 30 & 3 & 165 \\
Fatmawati - Majapahit & 74 & 88 & 3 & 165 \\
\hline
\end{tabular}

Tabel 7. Arus Lalu Lintas

\begin{tabular}{ccccccc}
\hline \multirow{2}{*}{ Waktu Survey } & \multicolumn{6}{c}{ Arus Lalu Lintas (smp/jam) } \\
\cline { 2 - 7 } & \multicolumn{2}{c}{ Timur } & \multicolumn{2}{c}{ Barat } & \multicolumn{2}{c}{ Selatan } \\
\cline { 2 - 7 } & ST & LT & ST & RT & RT & LT \\
\hline Senin (06.30-07.30) & 2419,3 & 943,7 & 2354,7 & 2050,6 & 745,8 & 2091,2 \\
Senin (12.00-13.00) & 2374,7 & 887,8 & 2128,9 & 1393,8 & 716,1 & 1772,4 \\
Senin (16.00-17.00) & 2337,8 & 537,6 & 1967,1 & 1630,6 & 730,9 & 1766,3 \\
Rabu (06.30-07.30) & 2351,8 & 573,9 & 2113,4 & 1813,7 & 727,4 & 1669,7 \\
Rabu (12.00-13.00) & 2332,9 & 686,3 & 2157,2 & 1552,5 & 734,6 & 1730,1 \\
Rabu (16.00-17.00) & 1877,2 & 623,9 & 2259,6 & 1743 & 639,9 & 1789,6 \\
Sabtu (06.30-07.30) & 1931,9 & 526 & 2233,9 & 1667,3 & 711,9 & 1746 \\
Sabtu (12.00-13.00) & 2354,5 & 782,5 & 2137,7 & 1749,4 & 685,4 & 1720,7 \\
Sabtu (16.00-17.00) & 2354,7 & 727,1 & 2347,8 & 1786,9 & 736,2 & 1704,3 \\
\hline MAX & 2419,3 & 943,7 & 2354,7 & 2050,6 & 745,8 & 2091,2 \\
\hline
\end{tabular}

Pada Tabel 7 dapat dilihat bahwa nilai arus lalu lintas tertinggi terjadi pada hari Senin pukul 06.30 - 07.30. Setelah didapatkan nilai tertinggi, maka dapat dilakukan analisis untuk mengetahui kinerja dari persimpangan J1. Brigjen Sudiarto - Jl. Majapahit. Dapat dilihat pada Tabel 8, yaitu nilai kinerja simpang pada kondisi eksisting.

Tabel 8. Kinerja Simpang Pada Kondisi Eksisting

\begin{tabular}{cccccccccc}
\hline $\begin{array}{c}\text { Kode } \\
\text { Pendekat }\end{array}$ & So & S & Q & C & DS & QL & NS & D & LOS \\
\hline T-ST & 6060 & 5757 & 2419,3 & 2442,4 & 0,991 & 218,1 & 1,05 & 196,3 & E \\
T-LT & 5640 & 5358 & 943,7 & 2273,1 & 0,451 & 64,3 & 0,65 & 121,6 & A \\
S-ST & 8520 & 8094 & 2354,7 & - & - & - & - & - & - \\
B-RT & 5820 & 5529 & 2050,6 & 2178,1 & 0,941 & 186,7 & 0,93 & 174,4 & E \\
S-RT & 4320 & 4104 & 754,8 & 746,2 & 0,999 & 94,9 & 1,26 & 233,7 & E \\
S-LT & 4320 & 4061 & 2091,2 & 2165,8 & 0,966 & 256,2 & 0,97 & 180,4 & E \\
\hline
\end{tabular}


Dimana:

So $\quad=$ Arus Jenuh Dasar (smp/jam)

$\mathrm{S}=$ Arus Jenuh (smp/jam)

$\mathrm{Q} \quad=$ Arus Lalu Lintas (smp/jam)

$\mathrm{C}=$ Kapasitas (smp/jam)

DS = Derajat Kejenuhan

$\mathrm{QL} \quad=$ Panjang Antrian $(\mathrm{m})$

NS $=$ Angka Henti

$\mathrm{D} \quad=$ Tundaan $(\operatorname{det} / \mathrm{smp})$

LOS = Level of Service / Tingkat

Pelayanan
Dari analisa yang telah dilakukan, didapat Level of Service (LOS) dengan nilai E yang berarti bahwa volume lalu lintas pada pesimpangan Jl. Brigjen Sudiarto - Jl. Majapahit mendekati atau berada pada kapasitas yang tersedia, arus tidak stabil, kecepatan kadang terhenti. Maka dari itu penulis melakukan rekayasa pada waktu sinyal dan menambah lebar jalan. Hasil rekayasa yang telah dilakukan dapat dilihan pada Tabel 9.

Tabel 9. Kinerja Simpang Pada Kondisi Proposed

\begin{tabular}{cccccccccc}
\hline $\begin{array}{c}\text { Kode } \\
\text { Pendekat }\end{array}$ & So & S & Q & C & DS & QL & NS & D & LOS \\
\hline T-ST & 7200 & 6840 & 2419,3 & 3480 & 0,695 & 173 & 0,68 & 196,3 & B \\
T-LT & 5640 & 5358 & 943,7 & 2726 & 0,346 & 56,9 & 0,56 & 121,6 & A \\
S-ST & 8520 & 8094 & 2354,7 & - & - & - & - & - & - \\
B-RT & 7200 & 6840 & 2050,6 & 3200 & 0,641 & 152,6 & 0,69 & 174,4 & B \\
S-RT & 6000 & 5700 & 754,8 & 1167 & 0,639 & 90 & 0,83 & 233,7 & B \\
S-LT & 6000 & 5700 & 2091,2 & 3267 & 0,640 & 186 & 0,61 & 180,4 & B \\
\hline
\end{tabular}

Dimana:

So $\quad=$ Arus Jenuh Dasar (smp/jam)

$\mathrm{S} \quad=$ Arus Jenuh $(\mathrm{smp} / \mathrm{jam})$

$\mathrm{Q}=$ = Arus Lalu Lintas (smp/jam)

$\mathrm{C}=$ Kapasitas ( $\mathrm{smp} / \mathrm{jam}$ )

DS = Derajat Kejenuhan

$\mathrm{QL}=$ Panjang Antrian $(\mathrm{m})$

NS = Angka Henti

$\mathrm{D} \quad=$ Tundaan $(\operatorname{det} / \mathrm{smp})$

LOS = Level of Service / Tingkat

Pelayanan

Pada Tabel 9. dapat dilihat bahwa nilai derajat kejenuhan menurun dan tingkat pelayanan simpang meningkat setelah dilakukan beberapa rekayasa. Tingkat pelayanan simpang memiliki nilai $\mathrm{B}$ sehingga arus stabil tetapi kecepatan operasi mulai dibatasi oleh kondisi lalu lintas, pengemudi memiliki kebebasan yang cukup untuk memilih kecepatan.

\section{SIMPULAN}

Berdasarkan hasil evaluasi dengan menggunakan metode Manual Kapasitas Jalan Indonesia 1997 yang telah dilakukan, maka dapat disimpulkan bahwa nilai dari volume lalu lintas (Q) pada setiap pendekat simpang hampir mendekati nilai dari kapasitas (C), dimana hal ini menunjukkan bahwa simpang Jalan Brigjen Sudiarto - Jalan Majapahit Jalan Fatmawati mengalami kepadatan. Hanya ada 1 (satu) pendekat yang memenuhi syarat dan pendekat tersebut tidak mengalami kemacetan yaitu pendekat Jl. Brigjen 
Sudiarto - Jl. Fatmawati (T-LT), dan pendekat lainnya memiliki nilai derajat jenenuhan (DS) di atas persyaratan yang telah ditetapkan oleh Manual Kapasitas Jalan Indonesia yakni 0,85 .

Tundaan simpang rata-rata pada simpang Jalan Brigjen Sudiarto Jalan Majapahit - Jalan Fatmawati memiliki nilai 141,320 det/smp. Tingkat pelayanan (Level of Service) berdasarkan parameter derajat kejenuhan (DS) memiliki nilai LOS E $(0,9-1,0)$ berarti bahwa jalan tersebut mempunyai karakteristik volume lalu lintas mendekati pada kapasitas, arus tidak stabil, dan kecepatan kadang terhenti. Tingkat pelayanan (Level of Service) berdasarkan parameter tundaan rata-rata simpang memiliki nilai $141,320 \mathrm{det} / \mathrm{smp}$ yang berarti nilai tingkat pelayanan $F(\geq 60$ det/smp) berarti pada simpang Jalan Brigjen Sudiarto - Jalan Majapahit Jalan Fatmawati memiliki arus terhambat, volume mendekati kapasitas dan kendaraan banyak berhenti.

Perubahan waktu sinyal dan penertiban hambatan samping mendapatkan hasil kurang efektif yakni masih memiliki kondisi kritis atau derajat kejenuhan (DS) mendekat persyaratan. Maka dari itu, perlu adanya penambahan lebar pendekat. Dari perhitungan yang telah kami lakukan, dengan adanya penambahan lebar pendekat mendapatkan hasil derajat kejenuhan (DS) di bawah dari persyaratan Manual Kapasitas Jalan Indonesia 0,85 dan memiliki tingkat pelayanan yang baik.

\section{DAFTAR PUSTAKA}

Badan Statistik Kota Semarang, 2018, Semarang Dalam Angka 2018. Semarang: BPS.

Jotin Khisty, C.J., B. Kent Lall., 2003, Dasar-Dasar Transportasi jilid 1 edisi ketiga. Erlangga. Jakarta.

Kementerian Perhubungan Republik Indonesia, 2006, Peraturan Menteri Perhubungan No. KM 14 Tahun 2006 Tentang Manajemen dan Rekayasa Lalu Lintas di Jalan. Kemenhub RI, Jakarta.

Manual Kapasitas Jalan Indonesia (MKJI), 1997, Departemen Pekerjaan Umum. Jakarta: Dirjen Bina Marga.

Morlok, E.K., 1998, Pengantar Teknik Lalu Lintas. Penerbit Elangga. Jakarta.

Pignarto, L.J., oius, 1973, Traffic Engineering Theory and Practice. USA : Prentice-Hall, inc.

Tamam, M.F., Arief, B., dan Rahmah A., 2016, Analisis Kinerja Simpang Bersinyal : Studi Kasus di Jalan Tegar Beriman - Jalan Raya Bogor. Jurnal Online Mahasiswa (JOM) Bidang Teknik Sipil. Volume 1, Nomor 1, Halaman 1-10. 